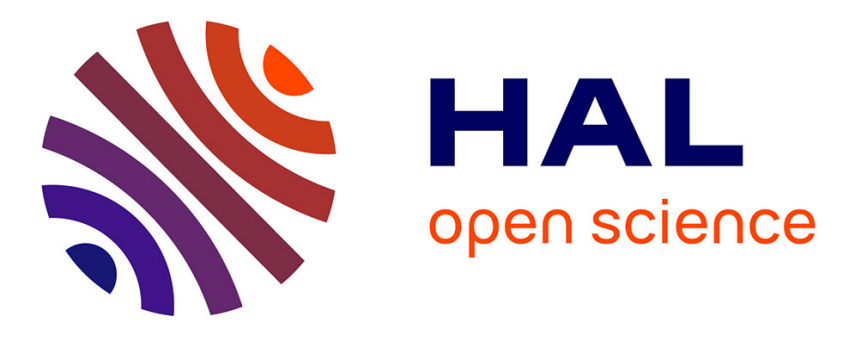

\title{
In vitro and in vivo cardioprotective and metabolic efficacy of vitamin E TPGS/Apelin
}

Patricia Leme Goto, Mathieu Cinato, Fadi Merachli, Bohdana Vons, Tony Jimenez, Dimitri Marsal, Nika Todua, Halyna Loi, Yohan Santin, Stéphanie Cassel, et al.

\section{To cite this version:}

Patricia Leme Goto, Mathieu Cinato, Fadi Merachli, Bohdana Vons, Tony Jimenez, et al.. In vitro and in vivo cardioprotective and metabolic efficacy of vitamin E TPGS/Apelin. Journal of Molecular and Cellular Cardiology, 2020, 138, pp.165-174. 10.1016/j.yjmcc.2019.12.001 . hal-02989450

\section{HAL Id: hal-02989450 https://hal.science/hal-02989450}

Submitted on 10 Nov 2020

HAL is a multi-disciplinary open access archive for the deposit and dissemination of scientific research documents, whether they are published or not. The documents may come from teaching and research institutions in France or abroad, or from public or private research centers.
L'archive ouverte pluridisciplinaire HAL, est destinée au dépôt et à la diffusion de documents scientifiques de niveau recherche, publiés ou non, émanant des établissements d'enseignement et de recherche français ou étrangers, des laboratoires publics ou privés. 


\section{Title}

\section{In vitro and in vivo cardioprotective and metabolic efficacy of vitamin E TPGS/Apelin}

Patricia Leme Goto ${ }^{1}$, Mathieu Cinato ${ }^{2,3}$, Fadi Merachli ${ }^{1}$, Bohdana Vons ${ }^{1}$, Tony Jimenez ${ }^{1}$, Dimitri Marsal $^{2,3}$, Nika Todua ${ }^{2,3}$, Halina Loy ${ }^{2,3}$, Yohan Santin ${ }^{2,3}$, Stéphanie Cassel ${ }^{1}$, Muriel Blanzat ${ }^{1}$, Helene Tronchere $^{2,3}$, Christophe Dejugnat ${ }^{1^{*}}$, Oksana Kunduzova ${ }^{2,3^{*}}$, Frederic Boal ${ }^{2,3,{ }^{*} \#}$

${ }^{1}$ Laboratoire des IMRCP, Université de Toulouse, CNRS UMR 5623, Université Toulouse III - Paul Sabatier

${ }^{2}$ INSERM U1048 I2MC, Toulouse, France

${ }^{3}$ Université Paul Sabatier, Toulouse, France

*equally contributed

"Corresponding author:

Frederic Boal

INSERM U1048 I2MC

Avenue Jean Poulhès

31432 Toulouse cedex 4

France

Tel: +33(0)531224117

E-mail: frederic.boal@inserm.fr

Short Title: TPGS/apelin in cardio metabolic disorder 


\section{Abstract}

2 Aims: Apelin and vitamin E have been proposed as signaling molecules, but their synergistic role is 3 unknown. The aim of this work was to develop vitamin E TPGS/Apelin system to test their 4 cardioprotective and metabolic efficacy in vitro and in vivo. Methods: FDA-approved surfactant D- $\alpha-$ 5 tocopheryl polyethylene glycol 1000 succinate (TPGS-1000) and Apelin complex were characterized 6 by physico-chemical methods (CMC determination, dynamic light scattering and circular dichroism). 7 In vitro studies were carried out on $\mathrm{H} 9 \mathrm{C} 2$ cardiomyoblasts and isolated murine cardiomyocytes. In 8 vivo studies were performed in isoproterenol- and high-fat diet-induced cardiac remodeling models 9 in mice. Results: We found that vitamin E TPGS/Apelin provide cardioprotective and metabolic efficacy in vitro and in vivo. In vitro studies revealed that vitamin E TPGS/Apelin reduces hypoxiainduced mitochondrial ROS production in cultured cardiomyocytes and H9C2 cardiomyoblasts. In addition, vitamin E TPGS/Apelin confers apoptotic response to hypoxic stress in cells. In a mouse model of isoproterenol-induced cardiac injury, TPGS is not able to affect cardiac remodeling, however combination of vitamin E TPGS and Apelin counteracts myocardial apoptosis, oxidative stress, hypertrophy and fibrosis. Furthermore, combination treatment attenuated obesity-induced cardiometabolic and fibrotic remodeling in mice. Conclusion: Together, our data demonstrated the therapeutic benefits of vitamin E TPGS/Apelin complex to combat cardiovascular and metabolic disorders. 


\section{Introduction}

23

The global prevalence of obesity and cardiovascular diseases has markedly increased over the past several decades in both developed and developing nations [1]. Apelin is a highly conserved peptide from the adipokine family and a key regulator of cardiovascular and metabolic status [2]. Apelin exerts strong inotropic actions [3] and regulates cardiac hypertrophy in response to pathological stress, activating the antioxidant enzyme catalase [4]. Apelin was also shown to reduce cardiomyocyte cell death [5,6] and fibrotic remodeling of the heart [7]. Moreover, it has been reported by us and others that apelin improves diabetic cardiomyopathy phenotype [8-10], promotes survival of transplanted mesenchymal cells [11] and that apelin plasma levels are increased in obese patients after myocardial infarction [5], opening new therapeutic avenues for the treatment of cardiovascular and metabolic disorders.

Vitamin $E$ is a fat-soluble antioxidant vitamin whose deficiency results from several chronic diseases associated with fat malabsorption, such as cystic fibrosis, Crohn's disease, chronic cholestasis, pancreatic insufficiency or gastric bypass in obese patients [12]. Antioxidant vitamins are commonly prescribed to patients after cardiac transplant, in order to limit oxidative stress and therefore transplant rejection [13]. Nevertheless, the clinical efficacy of vitamin E supplementation is not fully established [14-16]. In recent years, interest has grown on D- $\alpha$-tocopheryl polyethylene glycol 1000 succinate (TPGS-1000), a water-soluble derivative of natural vitamin E. TPGS-1000 is formed by the esterification of D- $\alpha$-tocopheryl succinate with polyethylene glycol (PEG), resulting in a hydrophilic polar PEG head and a lipophilic tocopheryl tail, providing TPGS-1000 with the amphipathic properties of surfactants [17]. TPGS-1000 is a GRAS (generally regarded as safe)-listed supplement and is FDAapproved as a drug solubilizer. Recently, it has been shown to be effective in several anti-cancer drug delivery systems, including doxorubicin [18] and curcumin [19], improving their therapeutic value. Moreover, it is widely used as a water-soluble vitamin E supplement for people with impaired uptake or chronic liver diseases, in particular in children with chronic cholestasis [20] and short bowel 
syndrome [21]. These disorders may affect cardiac function and predispose to the development of cardiomyopathy $[22,23]$. More recently, the effect of TPGS-1000 as a vitamin E alternative has been investigated in a rat model of cardiac transplant [24], opening new perspectives on the use of its surfactant properties in the field of cardiovascular diseases. In this context, combination of TPGS1000 and apelin is a promising approach to combat complex or multifactorial disorders including obesity and heart failure. However, Fo-to date, there is no study on the interactions of TPGS-1000 and apelin. In this study we characterized TPGS-1000/Apelin complex to test their cardioprotective benefits in vitro and in vivo. We found that TPGS-1000/Apelin complex counteracts adverse cardiometabolic and fibrotic remodeling in mice. In addition, in vitro studies revealed that TPGS1000/Apelin complex confers protection against hypoxia-induced cell death and oxidative stress.

Materials and Methods

Reagents

$\left[\right.$ Pyr $\left.^{1}\right]$-Apelin 13 (stated as apelin in the text) was purchased from Genecust Europe. D- $\alpha$-tocopheryl polyethylene glycol 1000 succinate (TPGS-1000), isoproterenol hypochloride and Hoechst 34580 were obtained from Sigma-Aldrich (France).

Cell culture and treatments

The H9C2 rat embryonic cardiomyoblastic cell line was cultured in DMEM medium (Life technologies) supplemented with $10 \%$ fetal bovine serum and $1 \%$ penicillin-streptomycin (Life technologies) in a $37^{\circ} \mathrm{C}, 5 \% \mathrm{CO}_{2}$ incubator. Primary cardiomyocytes were isolated from adult C57BL6/J mice hearts as previously described [25]. Cell viability was assessed using MTT (3-(4,5-Dimethyl-2-thiazolyl)-2,5diphenyl-2H-tetrazolium bromide) according to manufacturer's instructions (Sigma). For hypoxic treatment, cells were pretreated for 30 min with apelin $10^{-7} \mathrm{M}$ as described [5], TPGS-1000 or apelin+TPGS-1000 and subjected to normoxia $\left(5 \% \mathrm{CO}_{2}, 21 \% \mathrm{O}_{2}\right.$, balance $\left.\mathrm{N}_{2}\right)$ or hypoxia in a hypoxic 
chamber $\left(5 \% \mathrm{CO}_{2}, 1 \% \mathrm{O}_{2}\right.$, balance $\left.\mathrm{N}_{2}\right)$ for 2 hours for ROS production measurement and for 16 hours followed by a reoxygenation period of 4 hours for apoptosis evaluation. Quantification was performed as described [26].

\section{Evaluation of apoptosis and ROS production}

$\mathrm{H} 9 \mathrm{C} 2$ apoptosis was assessed by nuclear staining with $5 \mu \mathrm{g} / \mathrm{ml}$ Hoechst 34580 for $20 \mathrm{~min}$. Cells were then live-imaged on a wide-field Leica microscope. Pyknotic nuclei were counted and expressed as percentage of total nuclei. Apoptosis level on heart cryosections and cells was assessed using DeadEnd Fluorometric TUNEL system according to manufacturer's instructions (Promega). Mitochondrial superoxide levels on heart cryosections and cells were assessed with MitoSOX Red fluorescent probe (Life Technologies) and imaged by confocal microscopy as described [26].

\section{Cell lysate and Western-blotting}

Proteins from H9C2 cells were extracted using RIPA buffer supplemented with proteases inhibitors and western-blots were performed as described before [5]. Antibodies used are as follows: cleavedCaspase 3 from Cell Signaling Technology and RhoGDI from Santa Cruz.

\section{Animal studies}

The investigations conform to the Animal Care and Use Committee of the University of Toulouse, INSERM/ENVT and to the guidelines of the European Convention for the Protection of Vertebrate Animals used for Experimental and other Scientific Purposes (Council of Europe No 123, Strasbourg 1985). For isoproterenol induced cardiac hypertrophy, two-month-old C57BL6/J mice were pretreated with one intraperitoneal injection of vehicle only (PBS), apelin $(100 \mu \mathrm{g} / \mathrm{kg} / \mathrm{d})$, TPGS-1000 $(1.32 \mu \mathrm{mol} / \mathrm{kg} / \mathrm{d})$ or the combinatory therapy. Apelin amount used here was as described before [5] and the TPGS amount was set to maintain the Apelin:TPGS $1 / 20$ ratio as for the in vitro studies and 
physico-chemical characterizations. Mice were then treated with isoproterenol (i.p., $15 \mathrm{mg} / \mathrm{kg} / \mathrm{d}$ ) in the continuous presence of apelin, TPGS-1000, the combinatory therapy or vehicle only for 8 consecutive days. For obesity-linked cardiomyopathy, two-month old C57BL6/J mice were fed with high fat diet (HFD, 45\% fat, Research Diet D12451) for 14 months. HFD-fed mice were implanted with AZELT osmotic minipumps to deliver vehicle only (PBS) or the combinatory therapy apelin+TPGS1000 for 28 days. Glucose tolerance test was performed on fasted mice by intraperitoneal injection of glucose $(1 \mathrm{~g} / \mathrm{kg})$. Blood glucose levels from tail vein were monitored over time using a glucometer (Accu-check, Roche Diagnostics). Echocardiographic studies were performed as described [26].

\section{Quantitative RT-PCR analysis}

Total RNAs were extracted from mice heart in Qiazol using FastPrep lysing matrix M tubes (MP Biomedicals) and further purified using RNAeasy mini kit (Qiagen). Total RNAs were reverse transcribed using superscript II reverse transcriptase (Invitrogen). Real time quantitative PCR was performed as previously described (Alfarano et al., 2014) on a StepOnePlus realtime PCR system (Thermo Fischer scientific). Primers used on this study are as follows: collagen I 5'TGTGTGCGATGACGTGCAAT-3' (forward) and 5'-GGGTCCCTCGACTCCTACA-3' (reverse); collagen III 5'AAGGCGAATTCAAGGCTGAA-3 (forward) and 5'- TGTGTTTAGTACAGCCATCCTCTAGA-3' (reverse) and alpha-SMA 5'-GTCCCAGACATCAGGGAGTAA-3' (forward) and 5'-TCGGATACTTCAGCGTCAGGA-3' (reverse); PGC1- $\beta$ 5'-TTGAgGtgttcGgtgagATtGTAG-3' (forward) and 5'GAAGGTGATAAAACCGTGCTTCTG-3' (reverse); ANP 5'-AGAGTGGGCAGAGACAGCAAA-3' (forward) and 5'-AAGGCCAAGACGAGGAAGAAG-3' (reverse); BNP 5'-GCACAAGATAGACCGGATCG-3' (forward) and 5'-CCCAGGCAGAGTCAGAAAC-3' (reverse).

\section{Morphology}

Hematoxylin-eosin (H/E) staining of heart cryosections was performed using standard method. Myocytes hypertrophy was assessed by measuring cardiomyocyte cross sectional area on either H/E 

or on fluorescent WGA stained cryosections. Cardiac fibrosis was assessed using sirius red staining according to standard method or by fluorescent WGA staining according to [27].

\section{Statistical analysis}

Data are expressed as mean+/-SEM. Comparison between two groups was performed by Student's two-tailed t-test while comparison of multiple groups was performed by one-way ANOVA followed by a Bonferroni's post hoc test using GraphPad Prism version 5.00 (GraphPad Software, Inc).

\section{Results}

\section{Cumulative protection of vitamin E TPGS/Apelin against mitochondrial oxidative stress}

We first investigated the dose-dependent effects of TPGS-1000 on H9C2 cell viability. As shown in Fig.1a, treatment with up to $2 \mu \mathrm{M}$ TPGS-1000 for $24 \mathrm{~h}$ did not alter cell viability. However, higher concentration decreased dramatically $\mathrm{H} 9 \mathrm{C} 2$ cell viability, down to $25 \%$ for $20 \mu \mathrm{M}$ treatment. Therefore, we used TPGS-1000 on H9C2 cells at $2 \mu \mathrm{M}$ final concentration throughout this study. In order to evaluate the antioxidant properties of TPGS-1000, apelin and vitamin E TPGS/Apelin complex, we measured mitochondrial $\mathrm{O}_{2}^{-}$production by MitoSOX Red staining of living $\mathrm{H} 9 \mathrm{C} 2$ cells exposed to hypoxia. As shown in Fig.1b, while hypoxia treatment induced an excessive production of mitochondrial ROS, treatment of cells with TPGS-1000 alone (Fig. 1b, HT) or apelin alone (Fig. 1b, HA) totally abrogated mitochondrial $\mathrm{O}_{2}^{-}$production induced by hypoxia. Interestingly, quantification indicates a cumulative effect of vitamin E TPGS/Apelin (Fig. 1b, HTA). As undifferentiated H9C2 cardiomyoblasts may not represent cardiomyocytes, we investigated the effect of TPGS-1000 and apelin on mitochondrial $\mathrm{O}_{2}^{-}$production in primary cardiomyocytes isolated from adult mice. As shown in Fig.1c, both apelin and TPGS-1000 strongly reduced mitochondrial $\mathrm{O}_{2}^{-}$production induced by hypoxia. Similarly to what we observed in $\mathrm{H} 9 \mathrm{C} 2$ cells, the combinatory therapy showed a cumulative anti-oxidant effect of TPGS1000 and apelin when added together (Fig. 1c). 
As TPGS-1000 is a well-known surfactant commonly used to formulate molecules, we investigated

143 the physico-chemical properties of TPGS-1000 in the presence of apelin. Surface tension measurements showed that the critical micelle concentration (CMC) of TPGS-1000 was affected by the presence of apelin, decreasing from $10 \mu \mathrm{M}$ to $4 \mu \mathrm{M}$ (supplementary Fig. 1a). This suggests that apelin slightly promotes the micellization of TPGS-1000. Moreover, some signs of a pre-aggregation could be detected at very low concentrations, confirming this hypothesis. In contrast, dynamic light scattering (DLS) measurements showed that apelin had no effect on the mean hydrodynamic radius of TPGS-1000 micelles, remaining at 8nm (supplementary Fig. 1b). Moreover, using circular dichroism spectroscopy we found that TPGS-1000 did not affect structuration of apelin: even if the profile was slightly affected by the presence of the surfactant, it remained typical of a coil conformation (supplementary Fig. 1c). Altogether these results indicate that, even if the two compounds might interact weakly in the mixture, the main properties of TPGS-1000 and apelin remained conserved without loss of activity.

\section{Vitamin E TPGS/Apelin counteracts hypoxia-induced apoptotic cell death in H9C2 cells}

Excessive ROS production is linked to mitochondrial damage, activation of apoptotic cascades and ultimately cell death [28]. We next evaluated the effects of Vitamin E TPGS/Apelin complex on hypoxia-induced apoptosis in $\mathrm{H} 9 \mathrm{C} 2$ cardiomyoblasts. Apoptotic cell death was assessed either by monitoring pyknotic nuclei (Fig. 2a and c) and by TUNEL staining (Fig. $2 b$ and d). Whereas apelin was potent to prevent hypoxia-induced apoptotic cell death, TPGS-1000 had no effect. Importantly, treatment of cells with Vitamin E TPGS/Apelin complex significantly reduced the number of apoptotic cells in $\mathrm{H} 9 \mathrm{C} 2$ cells under hypoxia (Fig. 2a-e). This was further confirmed by monitoring the cleavage of caspase 3, a bona fide marker of apoptotic cascade activation (Fig. 2e and f). This suggests that Vitamin E TPGS/Apelin provide protection against apoptosis under stress conditions. 
found that long term hypoxic challenge dramatically reduced PGC1- $\beta$ expression. Importantly, apelin, but not TPGS-1000, restored PGC1- $\beta$ level (Fig. 2g), suggesting that TPGS-1000, unlike apelin, is not able to induce mitochondrial biogenesis.

\section{Effect of Vitamin E TPGS/Apelin on isoproterenol-induced cardiac injury in vivo}

171 In order to investigate the effect of Vitamin E TPGS/Apelin in vivo, we resorted to a chemically172 induced cardiac remodeling mouse model. Isoproterenol (ISO) is a beta-adrenergic agonist commonly used in vivo to induce cardiac hypertrophy, ROS production and apoptosis [26]. As shown by hematoxylin-eosin staining, chronic treatment with ISO induced cardiac hypertrophy (Fig. 3a, H/E). These results were confirmed using the fluorescent probe wheat-germ agglutinin (Fig. 3a, WGA) and quantification of cross-sectional cardiomyocyte area (Fig. 3b). Strikingly, treatment with Vitamin E TPGS/Apelin complex or apelin attenuated ISO-induced cardiac hypertrophic response, while TPGS1000 treatment had no significant effects (Fig.3). Interestingly, TPGS-1000 did not alter apelin antihypertrophic properties (Fig.3, ISO+TPGS+A). This was further confirmed by measuring the expression levels of the hypertrophic markers ANP and BNP (Fig. $3 c$ and d). Next we explored the antioxidant properties of Vitamin E TPGS/Apelin complex versus apelin and TPGS-1000 in vivo. As shown in Fig. 4a, both TPGS/Apelin complex and apelin markedly decreased ISO-induced myocardial mitochondrial $\mathrm{O}_{2}^{-}$production in cardiac tissue, while TPGS-1000 had no effect. To examine the antiapoptotic activity of TPGS/Apelin complex versus TPGS-1000 and apelin in vivo, we resorted to the TUNEL-staining of apoptotic cells on heart cryosections. As shown in Fig. 4b, ISO-treatment induced an increase in myocardial apoptotic cell death, which was prevented in vitamin E TPGS/Apelin-

187 treated or apelin-treated mice. TPGS-1000 treatment did not affect ISO-induced apoptotic cell death 188 in cardiac tissue in treated animals. Together, these data revealed anti-apoptotic activity of vitamin E 189 TPGS/Apelin in cardiac remodeling in vivo. 
fibrosis using Sirius red and fluorescent WGA staining in cardiac tissue from ISO-induced myocardial injury. As shown in Fig. 5, treatment with ISO induced the development of a pronounced perivascular and interstitial fibrosis in mice. While vitamin E TPGS/Apelin complex or apelin was able to efficiently reduce cardiac fibrosis, TPGS-1000 had no anti-fibrotic activity in ISO-remodeled hearts (Fig. 5).

\section{Effect of vitamin E TPGS/Apelin on a HFD-induced diabetic cardiomyopathy}

We next examined the effects of vitamin E TPGS/Apelin on myocardial and metabolic remodeling in mice exposed to HFD for 14 months. HFD-feeding resulted in the development of glucose intolerance, insulin resistance (Fig. 6a and b) and increased body weight (Fig. 6c). Echocardiographic analysis revealed left ventricular dysfunction as shown by the reduced ejection fraction (Fig. 6d) and fractional shortening (Fig. 6e). Treatment with vitamin E TPGS/Apelin improved glucose tolerance in HFD-fed mice (Fig.6a and b). The anti-glycemic activity of the vitamin E TPGS/Apelin was associated with a reduction in body weight, although it did not reach statistical significance (Fig. 6c). Importantly, vitamin E TPGS/Apelin treatment preserved cardiac function in obese mice as shown by the increase in EF and FS (Fig. 6d and e). This was accompanied by a reduction of cardiac hypertrophy as shown by cardiomyocytes cross-sectional area measurements (Fig. 7a), a decrease in myocardial mitochondrial $\mathrm{O}_{2}^{-}$production (Fig. 7b) and apoptosis (Fig. 7c). Interestingly, the combinatory therapy is potent to reduce myocardial fibrosis in HFD-fed mice (Fig. 8a). These results were confirmed by qPCR analysis of the expression of the myocardial pro-fibrotic markers $\alpha$ SMA, collagen I and collagen III (Fig. 8b).

Taken together, our results show for the first time that vitamin E TPGS/Apelin behaves as a competitive cardioprotective and metabolic modulator of myocardial remodeling processes.

\section{Discussion}

Apelin and vitamin E TPGS have been largely recognized for their antioxidant properties $[4,17]$. However, to date, there is no study regarding the interactions of vitamin E TPGS and apelin. In this 
study we characterized vitamin E TPGS/Apelin complex to evaluate their cardioprotective benefits in

217 vitro and in vivo. We characterized the cardiometabolic efficacy of vitamin E TPGS/Apelin in the

218 progressive myocardial remodeling processes. In a mouse model of isoproterenol-induced cardiac injury, vitamin E TPGS/Apelin counteracts myocardial apoptosis, oxidative stress, hypertrophy and fibrosis. Furthermore, we provide the first evidence that vitamin E TPGS/Apelin attenuates obesityinduced cardiometabolic and fibrotic remodeling in mice. In vitro studies reveal vitamin E TPGS/Apelin-dependent antioxidant and anti-apoptotic reprogramming in cells under hypoxic stress.

223 We found that both TPGS-1000 and apelin protect cultured cardiomyoblasts and primary

224 cardiomyocytes against oxidative stress in hypoxic challenge in a cumulative manner. However, we show that TPGS-1000 is ineffective to prevent apoptotic cell death as compared to apelin treatment. This discrepancy between TPGS-1000 and apelin suggests that they may use separate pathways/mechanisms to exert their antioxidant properties. Indeed, we and others previously demonstrated that apelin, through the binding of its receptor AJP, 1/ triggers mitochondrial biogenesis through activation of the transcription factors TFAM and NRF1 [8], 2/ activates the antioxidant enzyme catalase [4], 3/ regulates the FoxO family of transcription factors [5,6] and 4/ activates the AMPK pathway [30]. On the other hand, TPGS-1000 is known to act through the 232 intracellular liberation of the vitamin E moiety, giving direct antioxidant action in cells, as previously 233 demonstrated in a rat cardiac transplant model [24]. Consistently, we found that TPGS-1000 is not 234 able to restore the expression of the mitochondrial biogenesis regulatory factor PGC1- $\beta$ after long235 term hypoxic challenge. This could explain the lack of effect of TPGS-1000 in long-term challenges, 236 both in vitro and in vivo.

237 In vivo, we found that vitamin E TPGS/Apelin counteracts cardiac hypertrophy, oxidative stress and 238 cardiomyocyte cell death induced by isoproterenol, culminating in reducing fibrotic remodeling of 239 the heart. However, we demonstrated that TPGS-1000 alone did not provide protection against 240 myocardial hypertrophy, oxidative stress, apoptosis and activation of fibrotic reprogramming of the 
myocardium. One might hypothesize that a poor bioavailability of TPGS-1000 in cardiac tissue could explain this lack of effect. Although TPGS-1000 is well tolerated in vivo and has a good bioavailability,

243 previous studies suggested that it has a weak tropism for cardiac tissue [31]. Our physico-chemical characterization shows that apelin slightly decrease the CMC of TPGS-1000 in solution, from $10 \mu \mathrm{M}$ to $4 \mu \mathrm{M}$, not reaching the non-toxic concentration of $2 \mu \mathrm{M}$. Nevertheless, we found here that chronic treatment with TPGS-1000 in mice failed to protect the heart against ISO-induced cardiac remodeling. Moreover, this is consistent with the fact that TPGS-1000 did protect neither cardiomyoblasts nor cardiomyocytes against H/R-induced apoptotic cell death in long term challenge.

TPGS-1000 is widely used for its surfactant properties, namely as a solubilizer, emulsifier and bioavailability enhancer to increase drug delivery [32]. The initial aim of this study was to combine apelin with TPGS-1000 in order to improve apelin cardioprotective effects. Our physico-chemical characterization shows that apelin slightly modify the CMC of TPGS-1000 in solution, from $10 \mu \mathrm{M}$ to

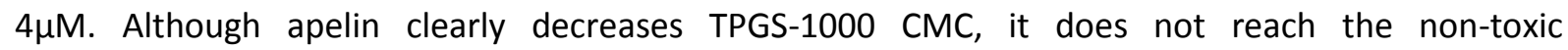
concentration of $2 \mu \mathrm{M}$ in vitro. More work needs to be done in order to decrease TPGS-1000 CMC in a concentration range compatible with cardiomyoblasts viability. Moreover, a recent study confirmed the cytotoxicity of TPGS-1000, showing that it induces cell cycle arrest and even apoptosis on breast cancer cells [33], and thus care must be taken for its use in drug delivery. TPGS/Apelin counteracts obesity-induced myocardial and metabolic abnormalities. Specifically, chronic treatment with TPGS/Apelin attenuated HFD-mediated cardiomyocyte death and cardiac dysfunction. In addition, we found that vitamin E TPGS/Apelin improved glucose tolerance in HFD-fed mice, suggesting that TPGS/Apelin modulates pathological remodeling of the diabetic heart in obese conditions. The development of treatments involving combinations of drugs is a promising approach 
the first evidence for the therapeutic benefits of vitamin E TPGS/Apelin to prevent cardiovascular and metabolic complications in obesity-linked heart failure. However, a limitation of this study is the absence of the apelin-treated HFD-fed mice. Nevertheless, we previously reported apelin-mediated $\underline{\text { cardioprotective responses to myocardial injury in HFD-induced obesity }[5,6] \text {. In isoproterenol- }}$ treated mice, apelin and vitamin E TPGS/Apelin complex have similar results, suggesting that the addition of vitamin E TPGS exerts no further benefit. The potential benefit of vitamin E TPGS/Apelin complex need to be further addressed in different experimental models of heart failure, such as $\underline{\text { transverse aortic constriction or ischemia-reperfusion. }}$

In summary, our findings demonstrated the protective effects of vitamin E TPGS/Apelin on adverse tissue reprogramming of the myocardium and metabolic defects in physiopathological context. Moreover, we revealed that oxidative stress and apoptotic cell death, key components in the development of cardiac injury, are attenuated by vitamin E TPGS/Apelin in both isoproterenol- and HDF-induced myocardial remodeling. These findings may lead to novel approaches for the treatment of adverse cardiovascular and metabolic complications linked to heart failure.

\section{Acknowledgements}

We thank the Cellular Imaging Facility Rangueil-I2MC-TRI. This work was funded by Région Occitanie (RBIO 14054336), INSERM, CNRS and Université Toulouse III.

\section{Disclosures}

The authors have no conflicts of interest to declare.

\section{Supplementary material}

Supplementary methods and figures are provided separately.

\section{References}

[1] Aurigemma GP, de Simone G, Fitzgibbons TP. Cardiac remodeling in obesity. Circ Cardiovasc Imaging. 2013; 6: 142-52. 
[2] Falcao-Pires I, Ladeiras-Lopes R, Leite-Moreira AF. The apelinergic system: a promising therapeutic target. Expert Opin Ther Targets. 2010; 14: 633-45.

[3] Kleinz MJ, Davenport AP. Emerging roles of apelin in biology and medicine. Pharmacol Ther. 2005; 107: 198-211.

[4] Foussal C, Lairez O, Calise D, Pathak A, Guilbeau-Frugier C, Valet P, et al. Activation of catalase by apelin prevents oxidative stress-linked cardiac hypertrophy. FEBS Lett. 2010; 584: 2363-70.

[5] Boal F, Roumegoux J, Alfarano C, Timotin A, Calise D, Anesia R, et al. Apelin regulates FoxO3 translocation to mediate cardioprotective responses to myocardial injury and obesity. Sci Rep. 2015; 5: 16104.

[6] Boal F, Timotin A, Roumegoux J, Alfarano C, Calise D, Anesia R, et al. Apelin-13 administration protects against ischaemia/reperfusion-mediated apoptosis through the FoxO1 pathway in high-fat diet-induced obesity. Br J Pharmacol. 2016; 173: 1850-63.

[7] Pchejetski D, Foussal C, Alfarano C, Lairez O, Calise D, Guilbeau-Frugier C, et al. Apelin prevents cardiac fibroblast activation and collagen production through inhibition of sphingosine kinase 1. Eur Hear J. 2012; 33: 2360-9.

[8] Alfarano C, Foussal C, Lairez O, Calise D, Attané C, Anesia R, et al. Transition from metabolic adaptation to maladaptation of the heart in obesity: role of apelin. Int J Obes. 2015; 39: 31220.

[9] Zeng H, He X, Hou X, Li L, Chen JX. Apelin gene therapy increases myocardial vascular density and ameliorates diabetic cardiomyopathy via upregulation of sirtuin 3. Am J Physiol Hear Circ Physiol. 2013; 306: H585-97.

[10] Ceylan-Isik AF, Kandadi MR, Xu X, Hua Y, Chicco AJ, Ren J, et al. Apelin administration ameliorates high fat diet-induced cardiac hypertrophy and contractile dysfunction. J Mol Cell Cardiol. 2013; 63: 4-13.

[11] Liang D, Han D, Fan W, Zhang R, Qiao H, Fan M, et al. Therapeutic efficacy of apelin on transplanted mesenchymal stem cells in hindlimb ischemic mice via regulation of autophagy. Sci Rep. 2016; 6: 21914.

[12] Azzi A. Many tocopherols, one vitamin E. Mol Aspects Med. 2018; 61: 92-103.

[13] Fang JC, Kinlay S, Beltrame J, Hikiti H, Wainstein M, Behrendt D, et al. Effect of vitamins C and $\mathrm{E}$ on progression of transplant associated arteriosclerosis: a randomised trial. Lancet. 2002; 359: 1108-13.

[14] Jaxa-Chamiec T, Bednarz B, Herbaczynska-Cedro K, Maciejewski P, Ceremuzynski L. Effects of vitamins $C$ and $E$ on the outcome after acute myocardial infarction in diabetics: $A$ retrospective, hypothesis-generating analysis from the MIVIT Study. Cardiology. 2009; 112: 219-23.

[15] Heart Protection Study Collaborative Group. MRC/BHF Heart Protection Study of antioxidant vitamin supplementation in 20,536 high-risk individuals: a randomised placebo-controlled trial. Lancet (London, England). 2002; 360: 23-33.

[16] Yusuf S, Dagenais G, Pogue J, Bosch J, Sleight P. Vitamin E supplementation and cardiovascular events in high-risk patients. The Heart Outcomes Prevention Evaluation Study Investigators. $\mathrm{N}$ Engl J Med. 2000; 342: 154-60. 
[17] Sadoqi M, Lau-Cam CA, Wu SH. Investigation of the micellar properties of the tocopheryl polyethylene glycol succinate surfactants TPGS 400 and TPGS 1000 by steady state fluorometry. J Colloid Interface Sci. 2009; 333: 585-9.

[18] Cao N, Feng S-S. Doxorubicin conjugated to d- $\alpha$-tocopheryl polyethylene glycol 1000 succinate (TPGS): Conjugation chemistry, characterization, in vitro and in vivo evaluation. Biomaterials. 2008; 29: 3856-65.

[19] Rachmawati H, Pradana A, Safitri D, Adnyana I. Multiple Functions of D- $\alpha$-Tocopherol Polyethylene Glycol 1000 Succinate (TPGS) as Curcumin Nanoparticle Stabilizer: In Vivo Kinetic Profile and Anti-Ulcerative Colitis Analysis in Animal Model. Pharmaceutics. 2017; 9: 24.

[20] Sokol RJ, Butler-Simon N, Conner C, Heubi JE, Sinatra FR, Suchy FJ, et al. Multicenter trial of dalpha-tocopheryl polyethylene glycol 1000 succinate for treatment of vitamin E deficiency in children with chronic cholestasis. Gastroenterology. 1993; 104: 1727-35.

[21] Traber MG, Schiano TD, Steephen AC, Kayden HJ, Shike M. Efficacy of water-soluble vitamin E in the treatment of vitamin E malabsorption in short-bowel syndrome. Am J Clin Nutr. 1994; 59: $1270-4$.

[22] Møller S, Henriksen JH. Cirrhotic cardiomyopathy: a pathophysiological review of circulatory dysfunction in liver disease. Heart. 2002; 87: 9-15.

[23] Fouad YM, Yehia R. Hepato-cardiac disorders. World J Hepatol. 2014; 6: 41-54.

[24] Nguyen TK, Nilakantan V, Felix CC, Khanna AK, Pieper GM. Beneficial effect of alphatocopheryl succinate in rat cardiac transplants. J Heart Lung Transplant. 2006; 25: 707-15.

[25] Fazal L, Laudette M, Paula-Gomes S, Pons S, Conte C, Tortosa F, et al. Multifunctional Mitochondrial Epac1 Controls Myocardial Cell Death. Circ Res. 2017; 120: 645-57.

[26] Tronchere H, Cinato M, Timotin A, Guitou L, Villedieu C, Thibault H, et al. Inhibition of PIKfyve prevents myocardial apoptosis and hypertrophy through activation of SIRT3 in obese mice. EMBO Mol Med. 2017; 9: 770-85.

[27] Emde B, Heinen A, Gödecke A, Bottermann K. Wheat germ agglutinin staining as a suitable method for detection and quantification of fibrosis in cardiac tissue after myocardial infarction. Eur J Histochem. 2014; 58: 2448.

[28] Tsutsui H, Kinugawa S, Matsushima S. Oxidative stress and heart failure. Am J Physiol Hear Circ Physiol. 2011; 301: H2181-90.

[29] González A, Schelbert EB, Díez J, Butler J. Myocardial Interstitial Fibrosis in Heart Failure. J Am Coll Cardiol. 2018; 71: 1696-706.

[30] Dray C, Knauf C, Daviaud D, Waget A, Boucher J, Buleon M, et al. Apelin stimulates glucose utilization in normal and obese insulin-resistant mice. Cell Metab. 2008; 8: 437-45.

[31] Tesan FC, Portillo MG, Moretton MA, Bernabeu E, Chiappetta DA, Salgueiro MJ, et al. Radiolabeling and biological characterization of TPGS-based nanomicelles by means of small animal imaging. Nucl Med Biol. 2017; 44: 62-8.

[32] Yang C, Wu T, Qi Y, Zhang Z. Recent Advances in the Application of Vitamin E TPGS for Drug Delivery. Theranostics. 2018; 8: 464-85.

[33] Neophytou CM, Constantinou C, Papageorgis P, Constantinou Al. d-alpha-tocopheryl 
polyethylene glycol succinate (TPGS) induces cell cycle arrest and apoptosis selectively in Survivin-overexpressing breast cancer cells. Biochem Pharmacol. 2014; 89: 31-42. 
Figure Legends

Fig. 1: Vitamin E TPGS/Apelin attenuates mitochondrial ROS production in H9C2 cells and cardiomyocytes . a. Rat H9C2 cardiomyoblasts were treated with increasing concentration of TPGS1000 for $24 \mathrm{~h}$ and cell viability was assessed by MTT staining. b-c. H9C2 cells (b) or cardiomyocytes isolated from adult mice (c) were pretreated for $30 \mathrm{~min}$ in the presence of apelin (A), TPGS-1000 (T) or the combinatory therapy (TA), and subjected to hypoxia $(\mathrm{H})$ or kept in normoxia $(\mathrm{N})$ for $2 \mathrm{~h}$. Mitochondrial $\mathrm{O}_{2}^{-}$production was assessed using MitoSOX red fluorescent probe. Cells were fixed and imaged by confocal microscopy. Scale bar is $10 \mu \mathrm{m}$. Quantification if shown on the right panels as mean+/-SEM. ${ }^{* * *} \mathrm{p}<0.001$ vs. $\mathrm{N} ; \$ \$ \$ \mathrm{p}<0.001$ vs. $\mathrm{H} ; \# \# \mathrm{p}<0.01$ between indicated conditions.

Fig. 2: Vitamin E TPGS/Apelin prevents apoptotic responses to hypoxic stress. a. H92C cells were treated with apelin (A), TPGS-1000 (T) or TPGS-1000+apelin (TA) for 30min before being submitted to hypoxia (16h) followed by $4 \mathrm{~h}$ re-oxygenation $(\mathrm{H})$ or kept in normoxia (N). Cell nuclei were stained with Hoechst-34580 and pyknotic nuclei were counted. b. Cells were treated as in a and apoptosis was assessed using TUNEL staining (in green). Cell nuclei are stained with DAPI (in blue). Arrowheads highlight TUNEL-positive cells. Bar is $20 \mu \mathrm{m}$. c-d. Quantification of pyknotic nuclei from a and TUNELpositive cells from $\mathbf{b}$. e. Cell lysates were probed with the indicated antibodies to assess caspase 3 cleavage. f. Quantification of caspase 3 cleavage from e. g. Expression level of PGC1b was assessed by RT-qPCR. Results are presented as mean+/-SEM from 3-6 independent experiments. ${ }^{* * *} p<0.001$ and $* p<0.05$ as compared with $N ; \$ \$ p<0.001, \$ \$ p<0.01$ and $\$ p<0.05$ as compared with $H$; ns, non significant.

Fig.3: Vitamin E TPGS/Apelin inhibits ISO-induced hypertrophic remodeling in vivo. a. Heart cryosections from mice treated as indicated were stained with hematoxylin/eosin (H/E) or with fluorescent WGA (in green). Bar is $25 \mu \mathrm{m}$ for H/E and 50 $\mu \mathrm{m}$ for WGA. b-d. Cardiomyoctyes crosssectional area (b), ANP (c) and BNP (d) levels are shown as mean+/-SEM. n=3-5 mice per group. ${ }^{* * *} p<0.001,{ }^{* *} p<0.01$ and ${ }^{*} p<0.05$ as compared with control; $\$ \$ p<0.001, \$ \$ p<0.01$ and $\$ p<0.05$ as 
compared with ISO-treated mice.

Fig.4: Antioxidant and anti-apoptotic properties of vitamin E TPGS/Apelin in cardiac remodeling in vivo. a. Oxidative stress was assessed in heart cryosections from mice treated as indicated. Bar is $50 \mu \mathrm{m}$. b. Myocardial apoptosis was assessed using TUNEL staining (in green) on heart cryosections.

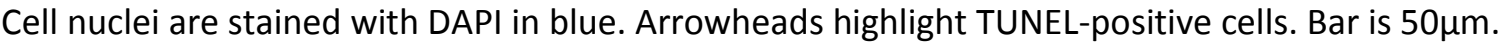
Quantifications are shown on the right panels as mean+/-SEM. ${ }^{* *} p<0.001$ and ${ }^{*} p<0.05$ vs. Control; $\$ p<0.05$ vs. ISO-treated mice. ns, non-significant.

Fig.5: Anti-fibrotic properties of vitamin E TPGS/Apelin in ISO-challenged hearts. Heart cryosections from mice treated as indicated were stained with fluorescent WGA (in green) or with Sirius red (SR) to highlight fibrotic area. Bar is $100 \mu \mathrm{m}$ for WGA and $25 \mu \mathrm{m}$ for SR. Quantification of fibrotic area is shown on the right. ${ }^{* *} p<0.01$ and ${ }^{*} \mathrm{p}<0.05$ vs. Control; $\$ p<0.05$ vs. ISO-treated mice.

Fig.6: Vitamin E TPGS/Apelin ameliorates cardiometabolic profile in obese mice. a. Glucosetolerance test was performed on 6h-fasted non-obese (ND), obese (HFD) or obese mice treated with TPGS-1000+apelin (HFD+TPGS+A). b. Area under the curve of glucose-tolerance test from a. c. Body weight of mice. d-e. Echocardiographic measures of ejection fraction (d, EF) and fractional shortening (e, FS) in mice. $\mathrm{n}=3-6$ mice per group. ${ }^{* *} \mathrm{p}<0.01$ and ${ }^{* * *} \mathrm{p}<0.001$ vs. ND; $\$ p<0.05$ vs. HFD mice.

Fig.7: Vitamin E TPGS/Apelin reduces cardiac hypertrophy, ROS production and apoptosis in obese mice. a. Heart cryosections from mice treated as in Fig.6 were stained with hematoxylin/eosin (H/E). Bar is $100 \mu \mathrm{m}$. Quantification of myocyte cross-sectional area is shown on the right panel. b. ROS production was assessed on heart cryosections from mice treated as indicated. Bar is $50 \mu \mathrm{m}$. c. Myocardial apoptosis was assessed using TUNEL staining (in green). Cell nuclei are stained with DAPI (in blue). Arrowheads highlight TUNEL-positive cells. Bar is $20 \mu \mathrm{m} .{ }^{* *} p<0.01$ and ${ }^{* * *} p<0.001$ vs. ND; $\$ \$ p<0.01$ and $\$ \$ p<0.001$ vs. HFD.

Fig.8: Vitamin E TPGS/Apelin reduces myocardial fibrosis in obese mice. a. Mice heart cryosections were stained with fluorescent WGA or Sirius red (SR). Bar is $25 \mu \mathrm{m}$ for SR or $100 \mu \mathrm{m}$ for WGA. 
Quantification of fibrotic area is shown on the right. b. Expression level of $\alpha$ SMA, collagen I (Col I) and collagen III (Col III) was assessed by qPCR from cardiac tissue. ${ }^{*} p<0.05$ and ${ }^{* * *} p<0.001$ vs. ND; $\$ p<0.05$ vs. HFD. 


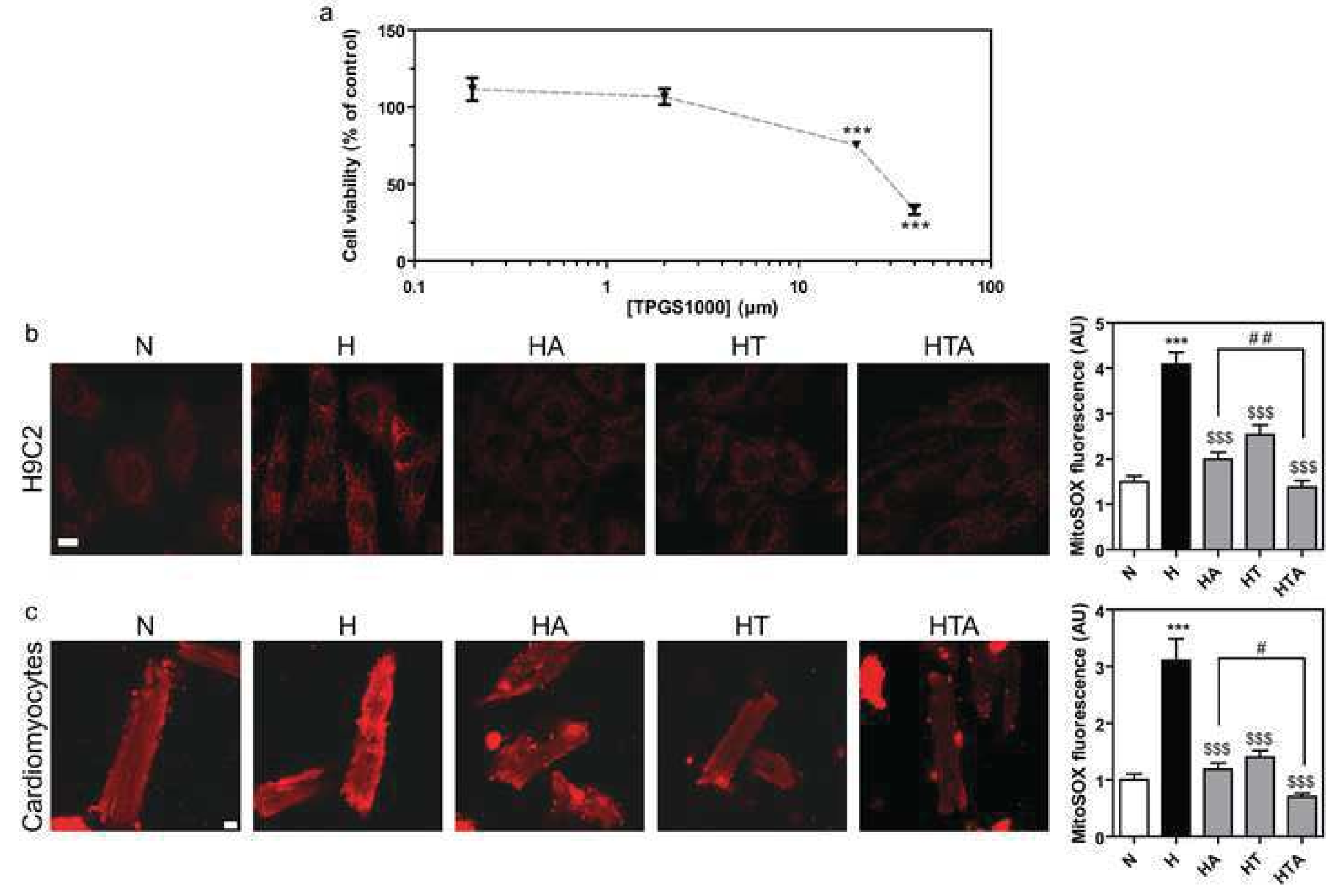


a

b
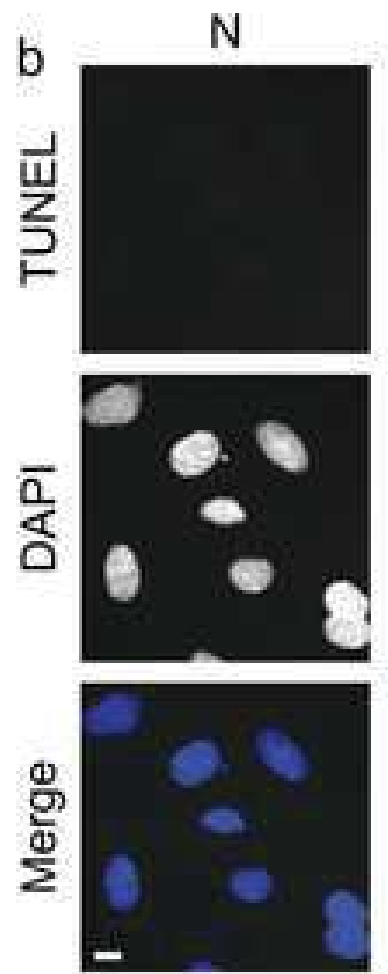

c
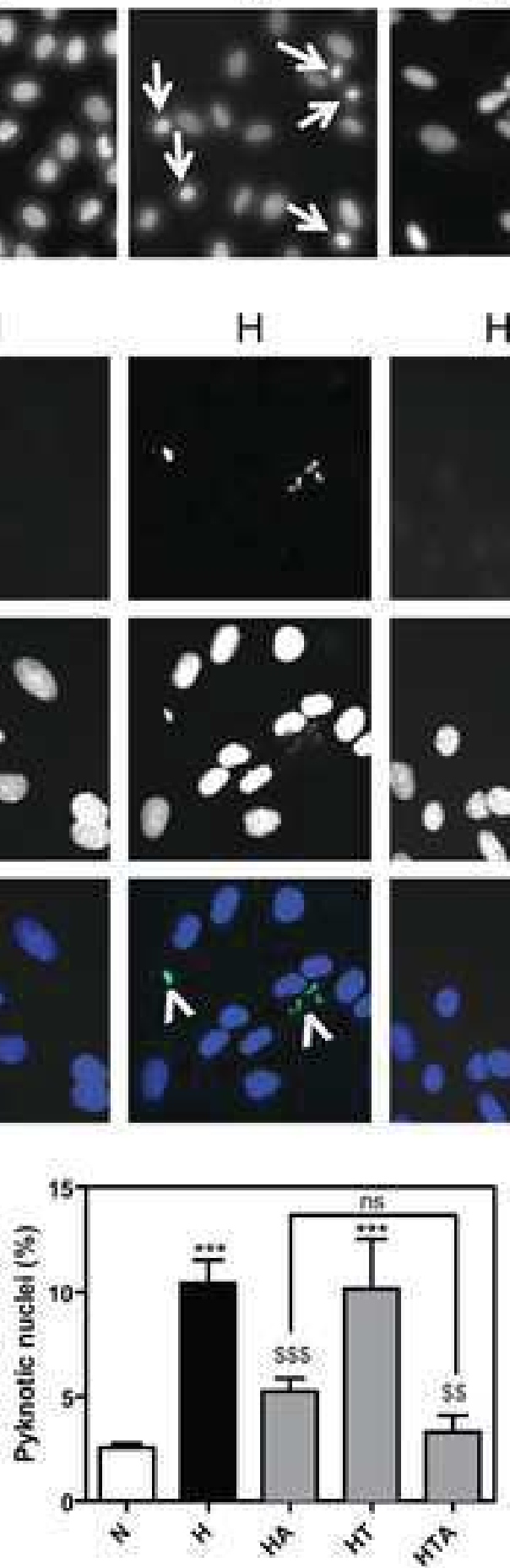

H
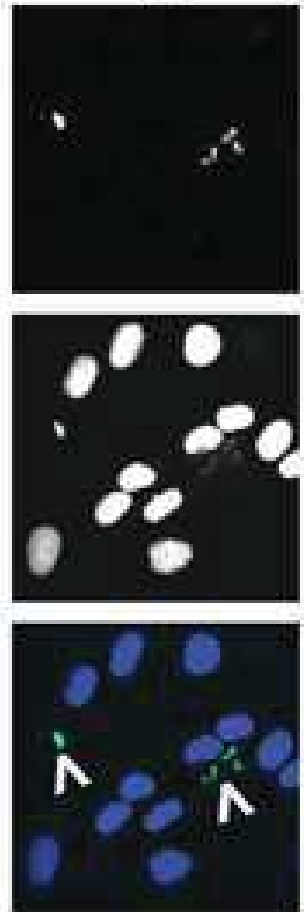
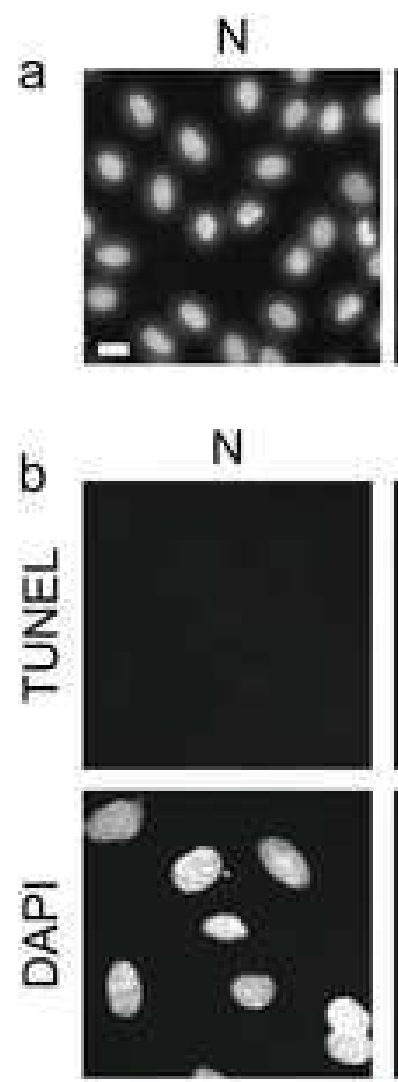

HA
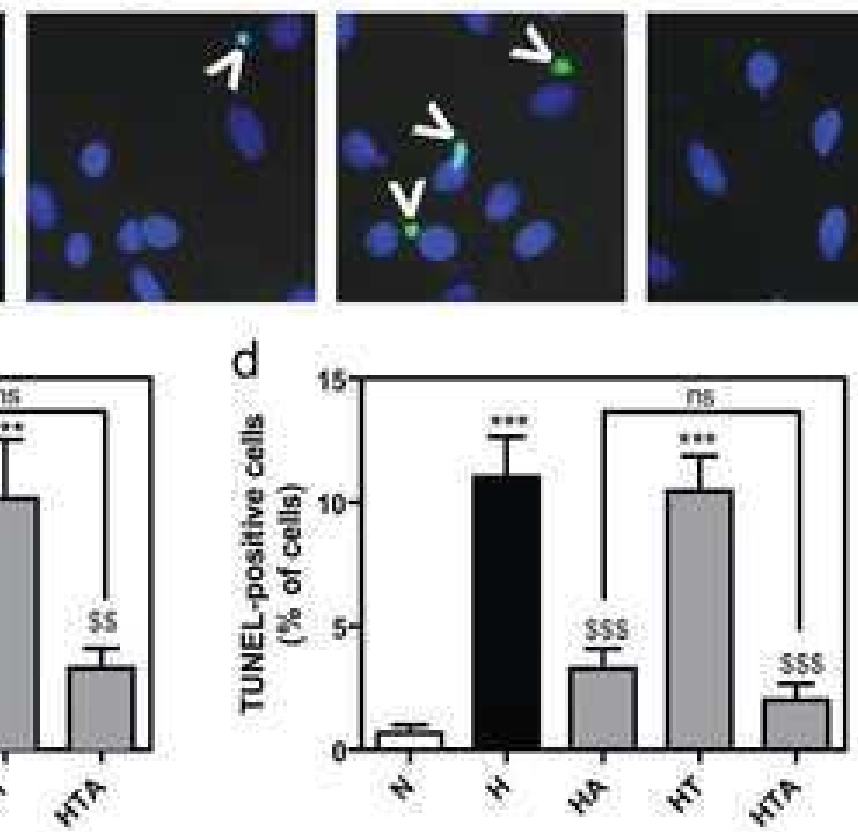

HTA

HTA
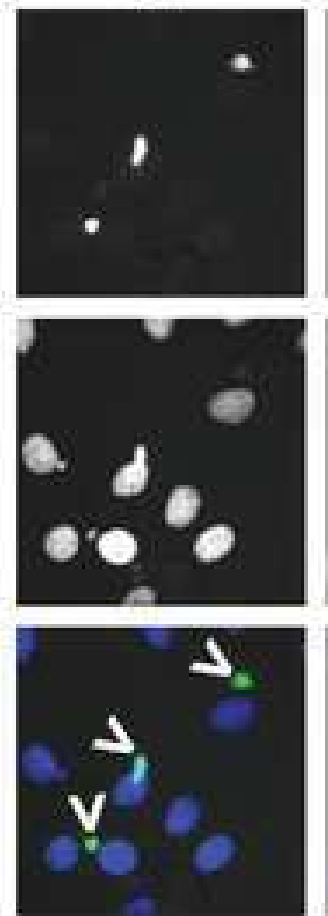
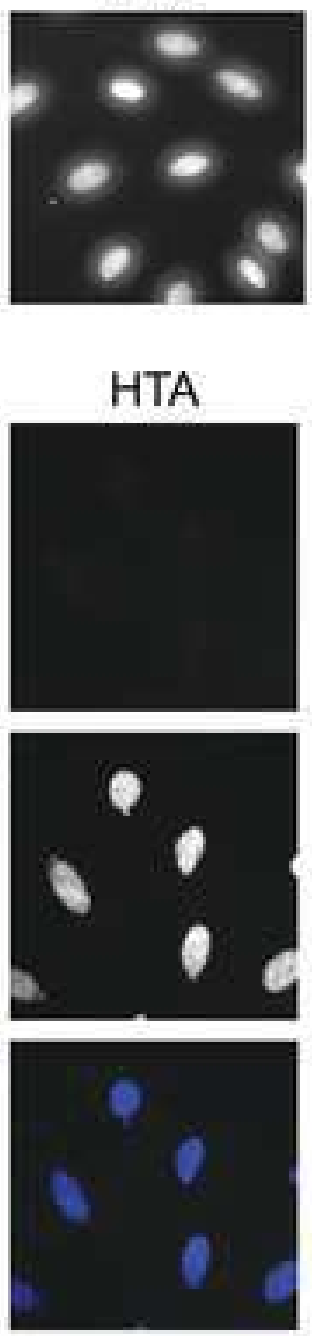

e
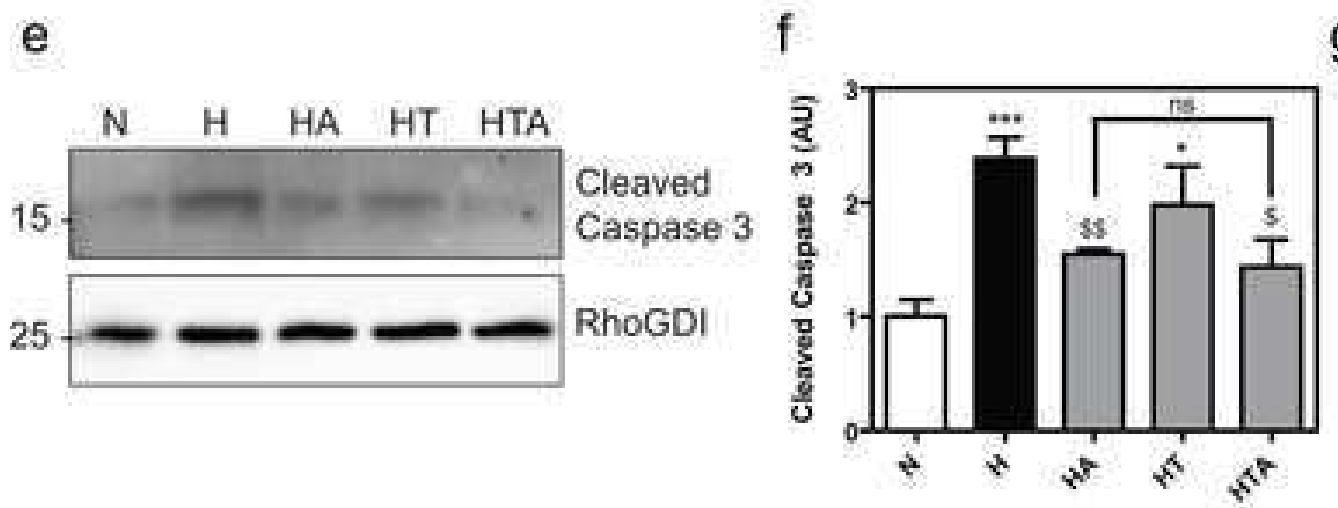

g

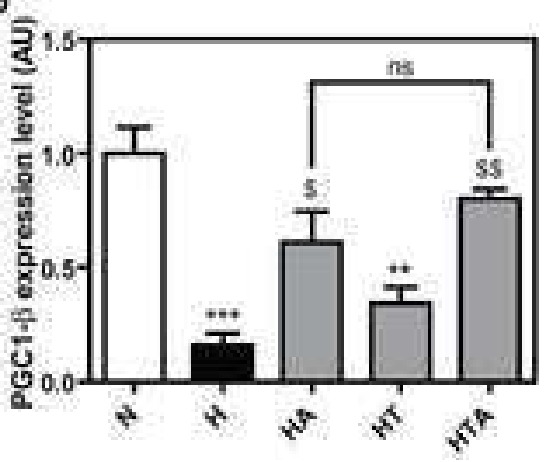



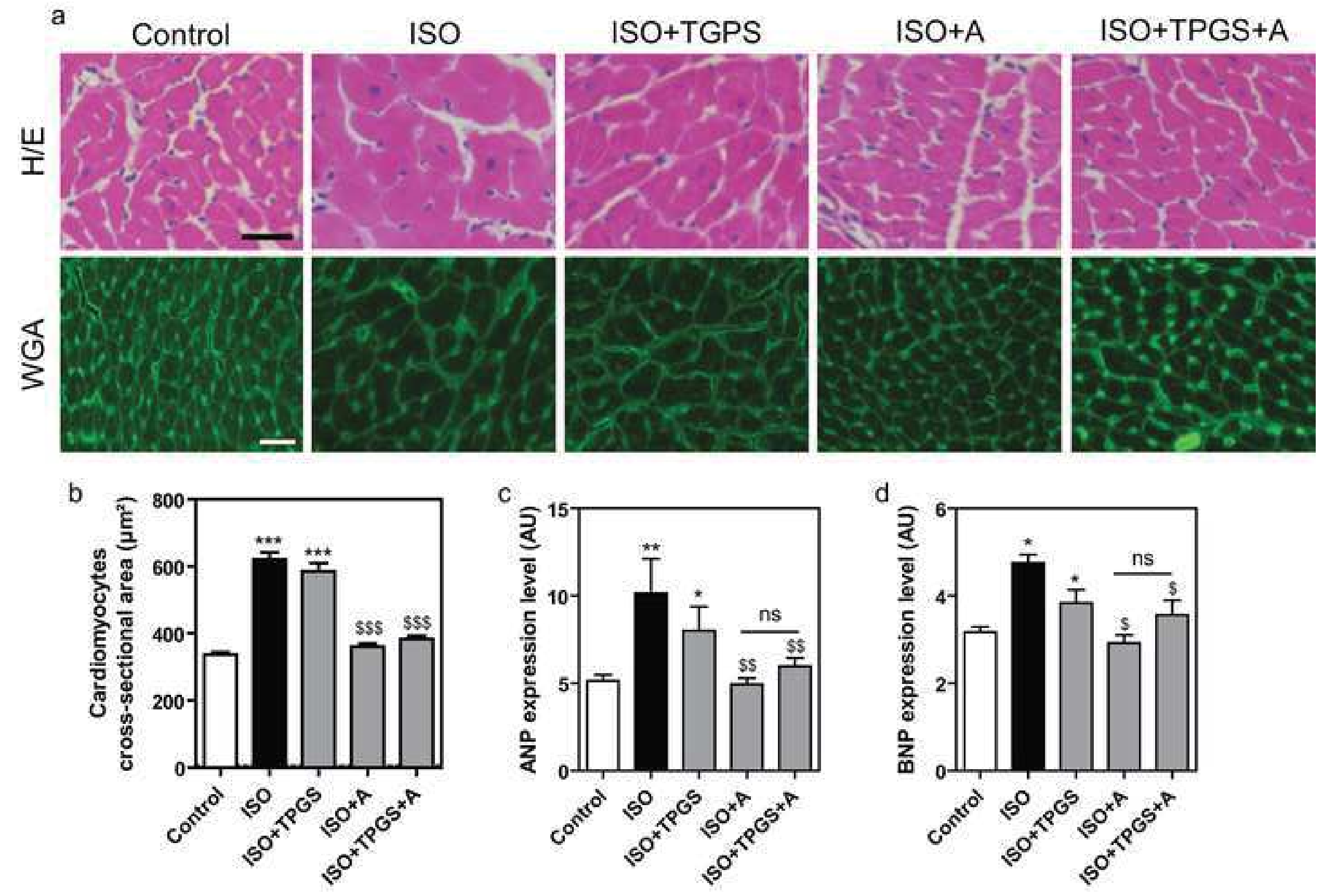


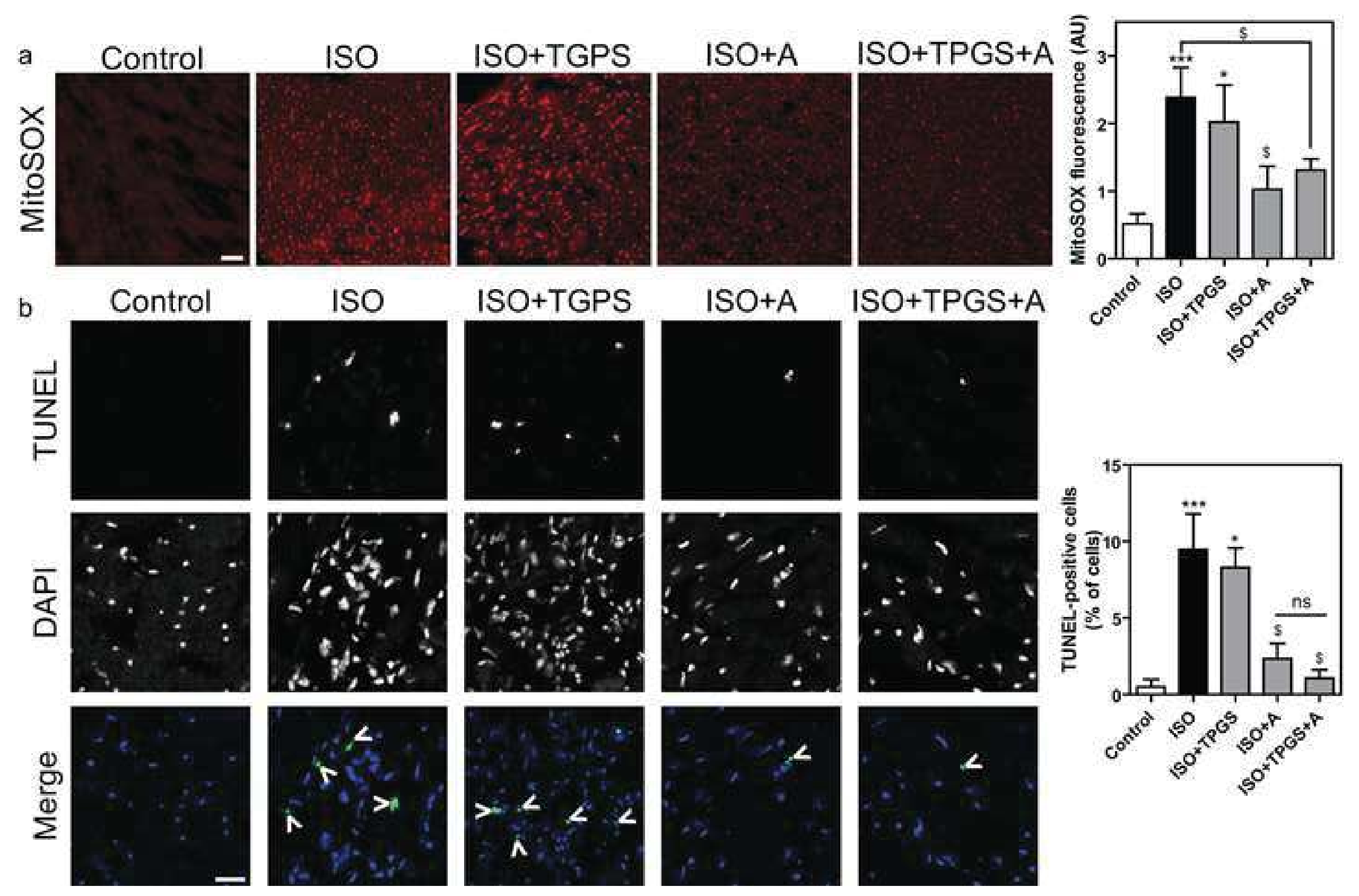



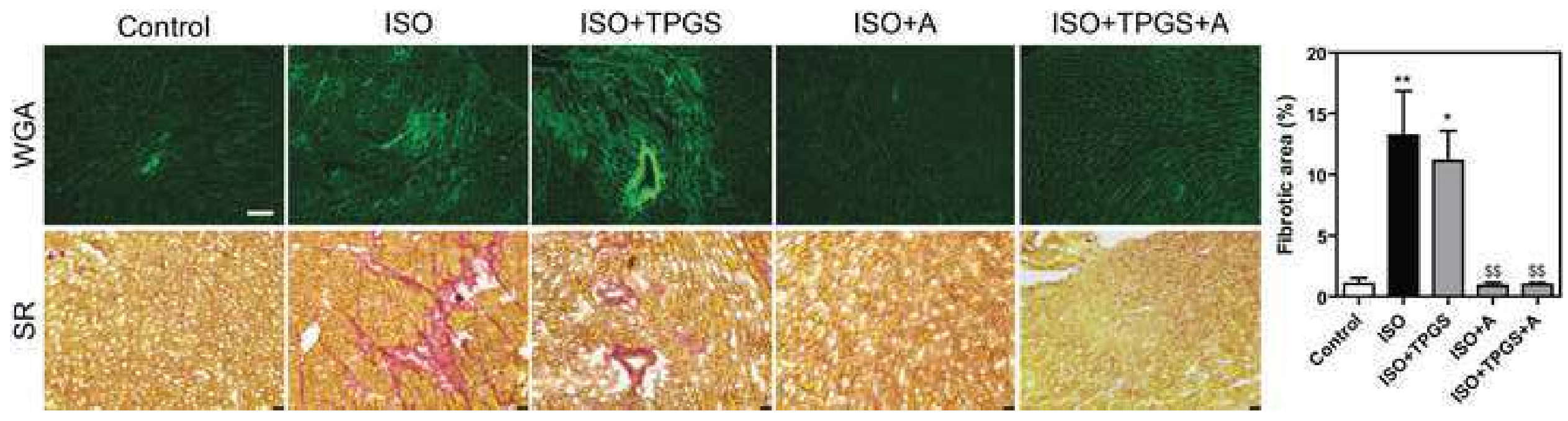

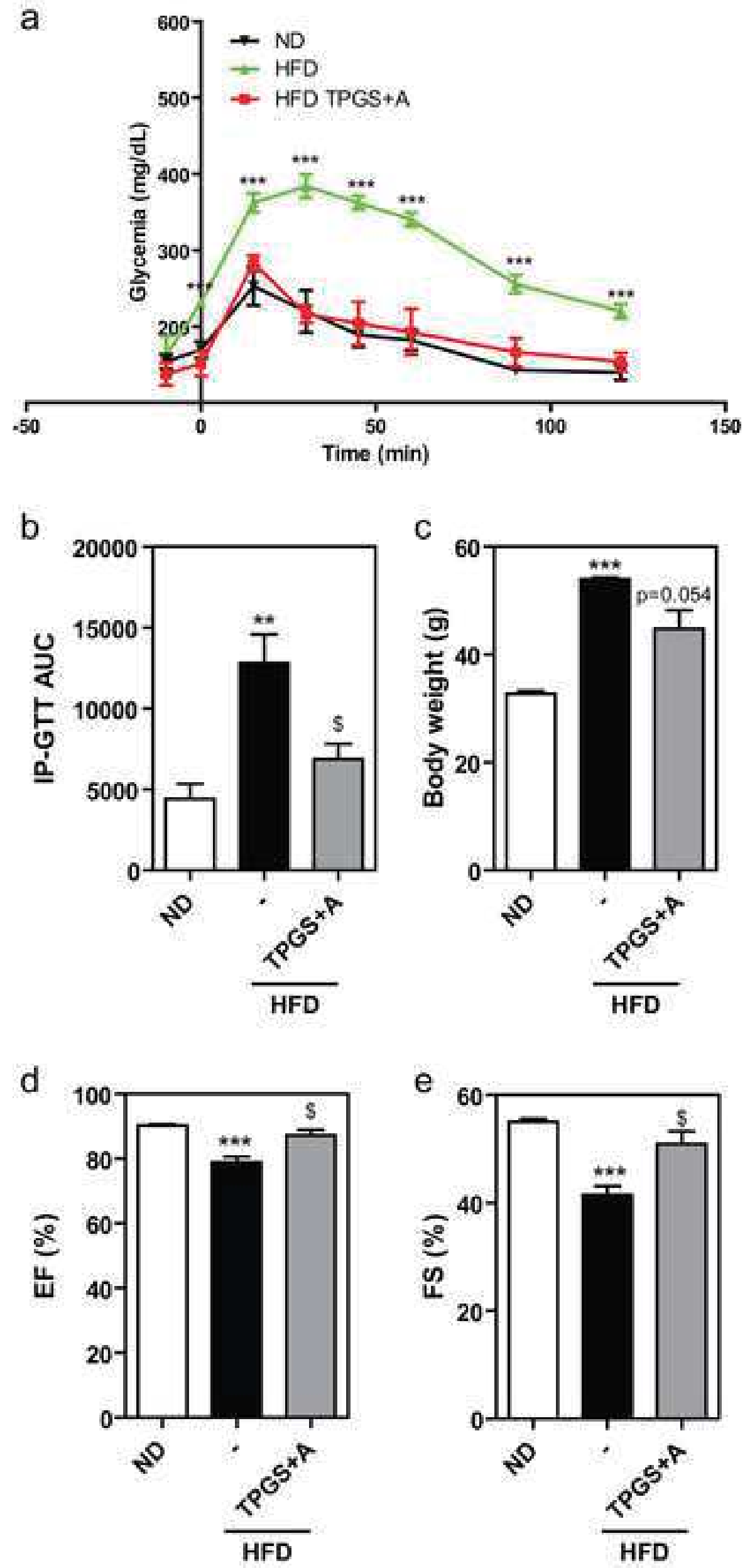
HFD
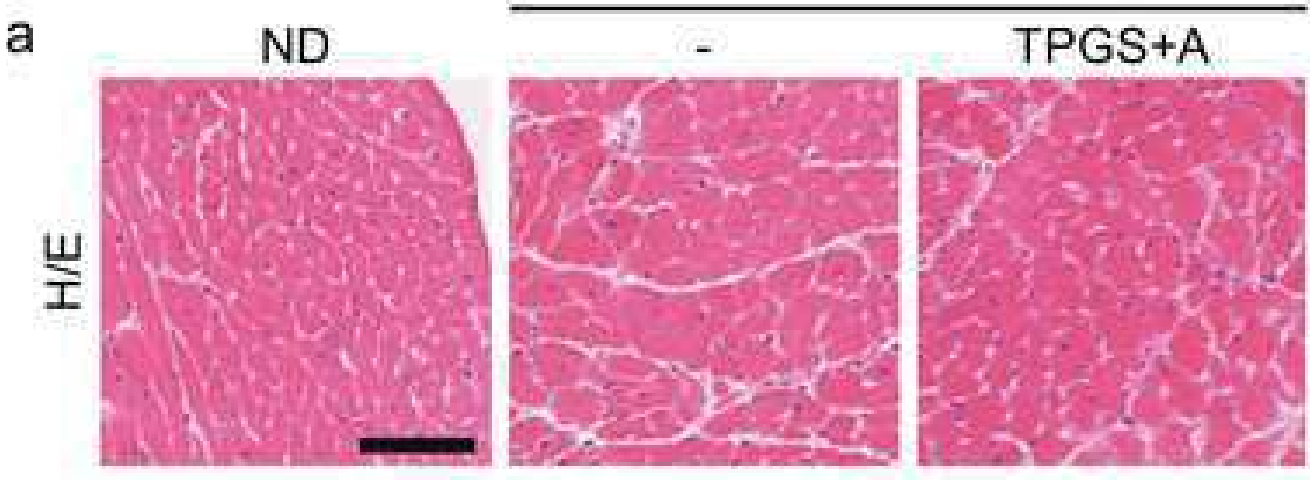

HFD

b

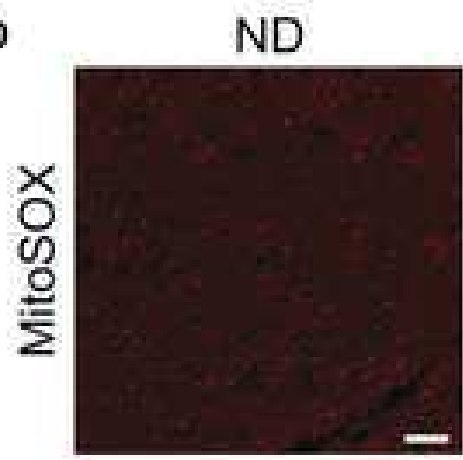

C
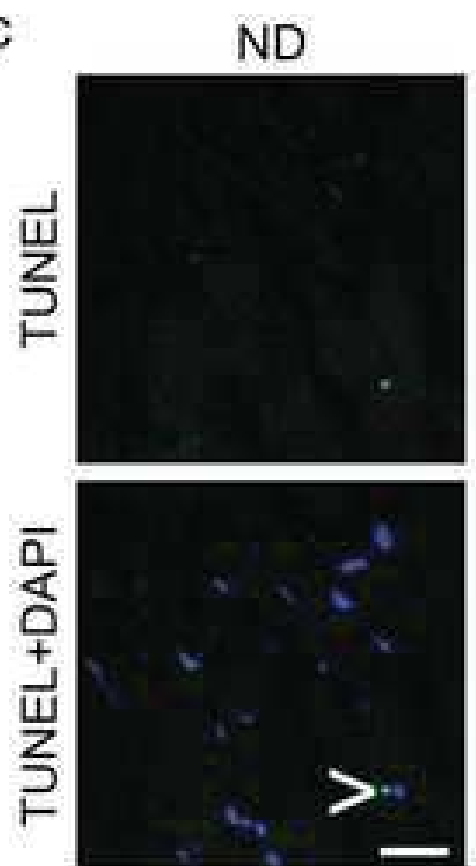

HFD

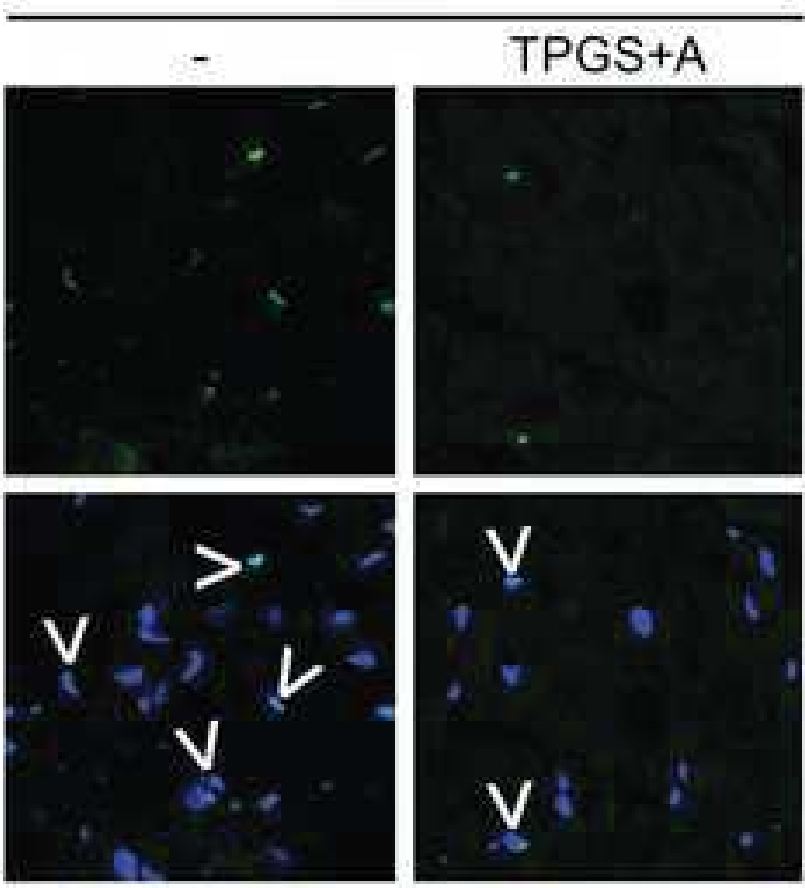

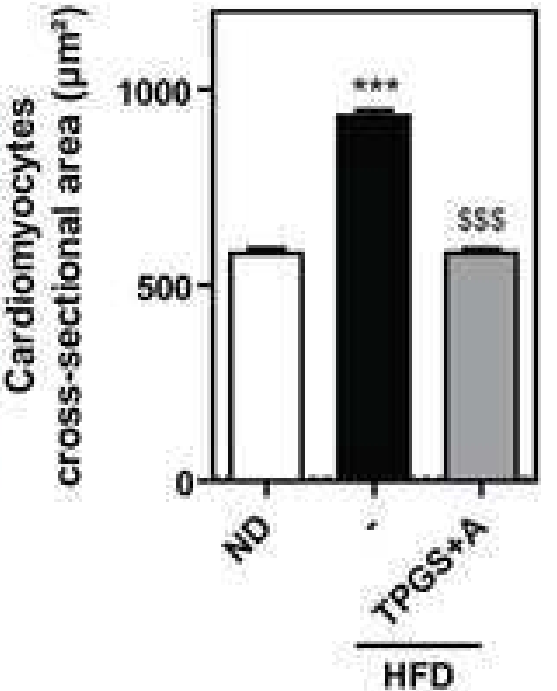
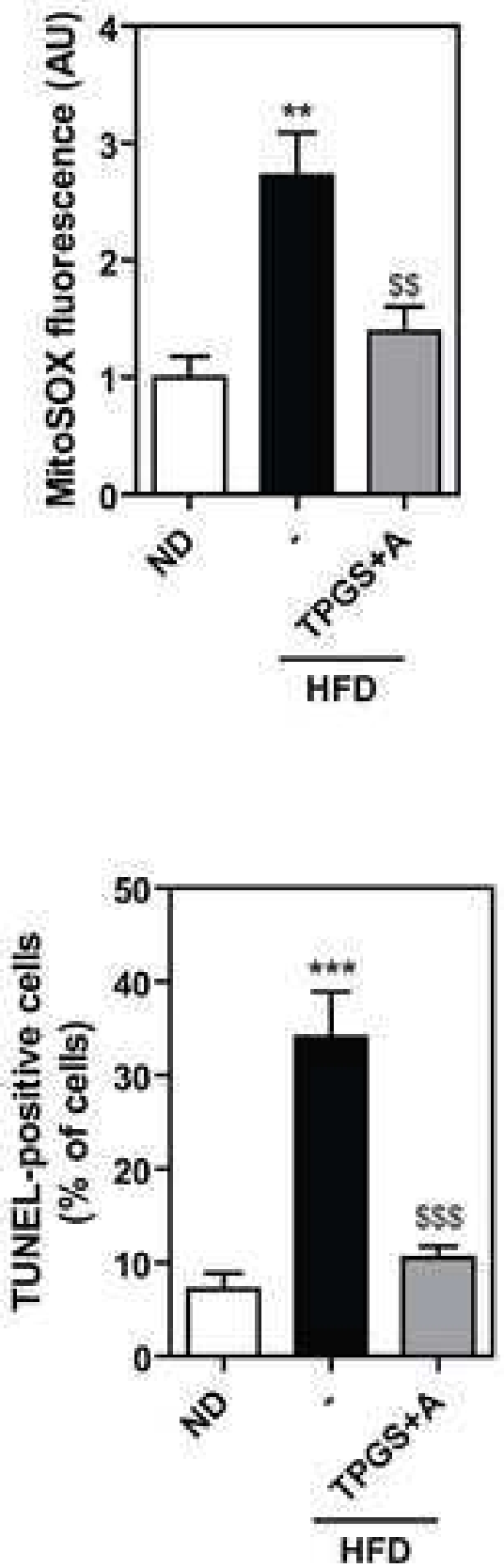
HFD
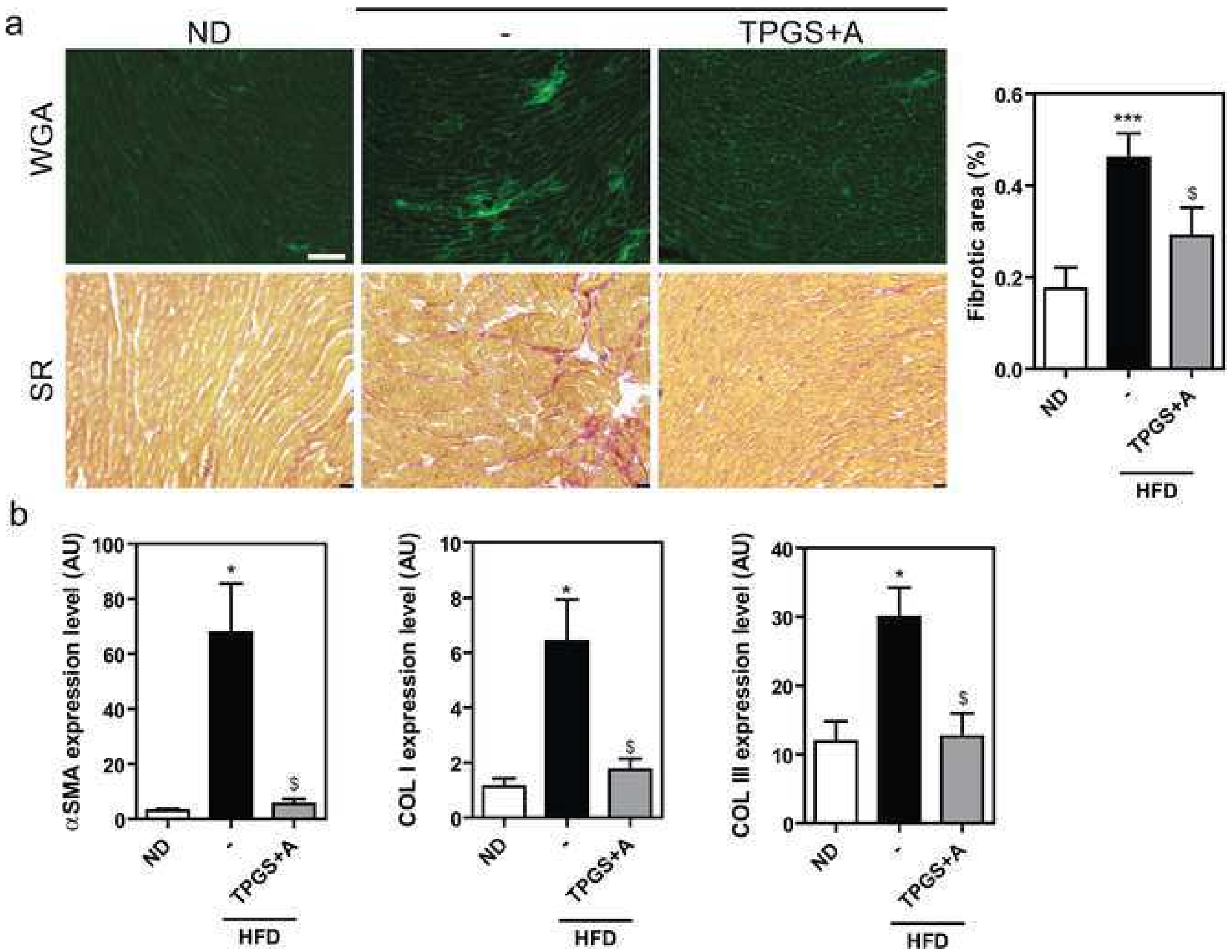
Click here to access/download Supplementary Material 2019-10-08 MS TPGS supp.docx 